\title{
Study of Solid-Liquid Ratio of Fly Ash Geopolymer as Water Absorbent Material
}

\author{
Fandi Angga Prasetya ${ }^{1,3, *}$, Ndaru Candra Sukmana ${ }^{2,3}$, and Ufafa Anggarini ${ }^{2,3}$ \\ ${ }^{1}$ Departement of Engineering Management, Universitas Internasional Semen Indonesia, Indonesia \\ ${ }^{2}$ Departement of Chemical Engineering, Universitas Internasional Semen Indonesia, Indonesia \\ ${ }^{3}$ Konsorsium Riset Geopolimer Indonesia (KORIGI), Lab Beton dan Bahan Bangunan ITS, Surabaya, \\ Indonesia
}

\begin{abstract}
Geopolymer has been synthesized from fly ash to be applicated as water absorbent material. This research conducted to determine the ability of geopolymer to abrsop water by variation of solid - liquid ratio at optimum molarity of $\mathrm{NaOH} ; 3 \mathrm{M}$. In this research, the synthesis of geopolymer was conducted at the variation of solid-liquid ratio; 60:40, $65: 35,70: 30$, and $75: 25$. Result of the treatment were characterized by XRD and SEM to compare the geopolymer structure. Water absorption capacity was measured by immersing the geopolymer specimens in water for 24 hours. Based on the result, solid - liquid ratio with maximum water absorbed was $70: 30$ with 13,04 wt $\%$.
\end{abstract}

\section{Introduction}

Urban farming is an activity utilizing the open space that is not productive (vacant land and green land) into an open space that is productive in quality and quantity. Planting medium is essential if urban farming is done in a narrow open space, with the right media plants can grow well. Planting medium as a place to grow plants must have several properties, one of which is capable of storing water [1]. Ceramic based porous material is one type of material that has the potential to be used as water absorbent. Water-absorbing material is especially useful as a planting medium in the narrow land or areas with limited land. Porous ceramics prepared from clay minerals indicate the adsorption capacity of the high water, high adsorption rate and slow water release rate associated with their unique microporous structure in the material $[2,3]$.

Geopolymer is one of the best candidates in preparing a porous ceramic material. Geopolymer can be synthesized and undergo a process of hardening at room temperature with the formation of gel alkali aluminosilicate framework structure. Geopolymer synthesis is generally carried out by reacting the alkali silicate solution with a solid aluminosilicate such as metakaolin, fly ash and so forth under alkaline conditions $[4,5]$. Microstructure and mechanical properties of the material is influenced by the chemical composition of the starting materia [6]. Duxson et al., [7] explains that the mechanical properties of geopolymer produced increased with increasing ratio of $\mathrm{SiO} 2 / \mathrm{Al} 2 \mathrm{O} 3$ is used in the synthesis process, while the porosity of the material increases with increasing ratio $\mathrm{H} 2 \mathrm{O} /$

\footnotetext{
* Corresponding author: fandi.prasetya@uisi.ac.id
} 
$\mathrm{SiO} 2$. In this research, the synthesis of geopolymer was conducted at the variation of solidliquid ratio; 60:40, 65:35, 70:30, and 75:25 at optimum molarity of $\mathrm{NaOH} ; 3 \mathrm{M}$. Result of the treatment were characterized by XRD and SEM to compare the geopolymer structure.

\section{Experimental section}

\subsection{Material and Instrumentation}

The materials used in this research were fly ash. The fly ash refers to industrial waste collected from a power plant in Paiton area which is used as the aluminosilicate source. $\mathrm{Na}_{2} \mathrm{SiO}_{3}, \mathrm{NaOH}$ pellet (99\%, Merck) as alkali activator, distilled water and $\mathrm{KCl}$. X-ray Diffraction (XRD) was conducted to identify the crystal phase of geopolymer by using $\mathrm{Cu}$ $\mathrm{K} \alpha$ radiation. Scanning Electron Microscope (SEM) images were used to identify the morphology of geopolymer. The water storage capacities of all geopolymer samples were defined by immersing geopolimer matrix in distilled water for 24 hour at $25^{\circ} \mathrm{C}$.

\subsection{Procedure}

This material was prepared by shieving with sieve no. 325 and dried at $85^{\circ} \mathrm{C}$ for 24 hours. $\mathrm{NaOH}$ solution was prepared using $\mathrm{NaOH}$ pellet with distilled water. The solution was stored for 24 hours. Alkali solution was prepared by mixing sodium silicate with $\mathrm{NaOH}$ solution. The synthesis of geopolymer was conducted at the variation of solid-liquid ratio; $60: 40,65: 35,70: 30$, and 75:25 at optimum molarity of $\mathrm{NaOH} ; 3 \mathrm{M}$.Fly ash, as the starting material, was mixed with alkali solution, then $\mathrm{KCl}$ salt was added into geopolymer paste. This mixture was casted and cured at $85^{\circ} \mathrm{C}$ for 24 hours.

\subsection{Measurement of water absorption capacity}

Geopolymer specimen was weighed and determined as initial weight $\left(\mathrm{w}_{0}\right)$. These samples were then immersed in destilled water for 24 hours at $25^{\circ} \mathrm{C}$. The saturated dry surface was weighed as final weight $\left(\mathrm{w}_{\mathrm{f}}\right)$. Water absorption capacity was calculated and reported as percentage increase in weight.

\section{Result and discussion}

Geopolymer has been synthesized using fly ash and alkali solution. Abdullah, et al [8] stated that geopolymer containing silica and alumina will react to produce chain and ring that contain three dimensional polymer. The existance of three dimensional ring in geopolymer can be used for water and nutrient storage for plantation aplication. Okada et al, [9] stated that geopolymers are good candidates for water absorbers due to their microstructure.

\subsection{Effect of Solid/Liquid Ratio Toward the Structure}

The crystal phase of geopolymer samples were investigated by XRD. Fig. 1 showed that XRD pattern of Geopolymer with solid-liquid ratio 60:40 (a), 65:35 (b) 70:30, (c) , and 75:35(d) at $\mathrm{NaOH} 3 \mathrm{M}$ respectively. All variation of solid-liquid ratio has formed Geoplymer phase. Geopolymerization reaction can form phases, such as quartz, mullite, magnetite and sodalite. Fig. 1 show the XRD pattern of fly ash and geopolymer samples. 
While quartz was the phase most widely found at $(2 \theta)$ of $26.72^{\circ}, 39.49^{\circ}$ and $50.49^{\circ}$. The other phases found in fly ash sample was mullite shown from peak at $(2 \theta)$ of $16.48^{\circ}$, $23.47^{\circ}, 31.15^{\circ}, 33.2^{\circ}, 35.29^{\circ}, 40.89^{\circ}, 42.55^{\circ}, 49.52^{\circ}, 53.66^{\circ}$ and $57.56^{\circ}$. The diffractogram of geopolymer samples was synthesized from fly ash exhibit transformation from fly ash diffractogram. X-Ray diffraction pattern of geopolymer show the presence of hump peak at (20) of $11^{\circ}-40^{\circ}$ indicating the formation of geopolymer phase which has been done. However, the quartz phase could be found in geopolymer samples at (20) of $27^{\circ}$ that confirms partly fly ash that unreacted.

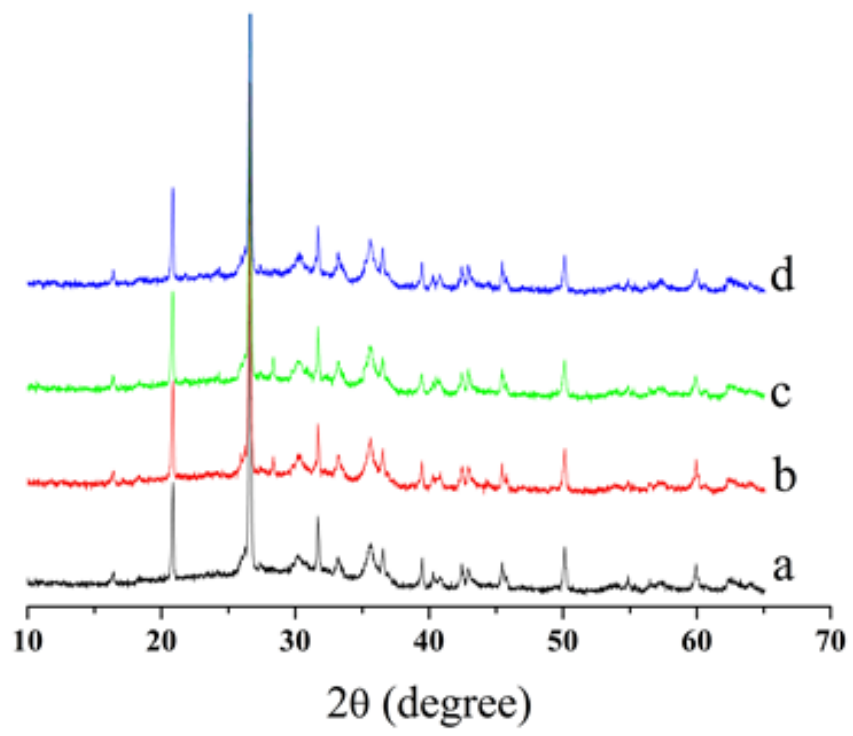

Fig. 1. The XRD pattern of Geopolymer with solid-liquid ratio 60:40 (a), 65:35 (b) 70:30, (c), and 75:35(d) at $\mathrm{NaOH} 3 \mathrm{M}$.

\subsection{Effect of solid/liquid weigt ratio toward the morphology of geopolymer}

Fig. 2 shows the morphology of geopolymer that synthesis with variation of solid/liquid weight ratio. Lloyd and Rangan (2010) in their experiement reveal that the smallest ratio generates geopolymer with higher workability and dense material. SEM images of geopolymer with solid/liquid weight ratio of 70:30 show the smallest particle size, so the material produce high specific area and high water abrsorption capacity. 

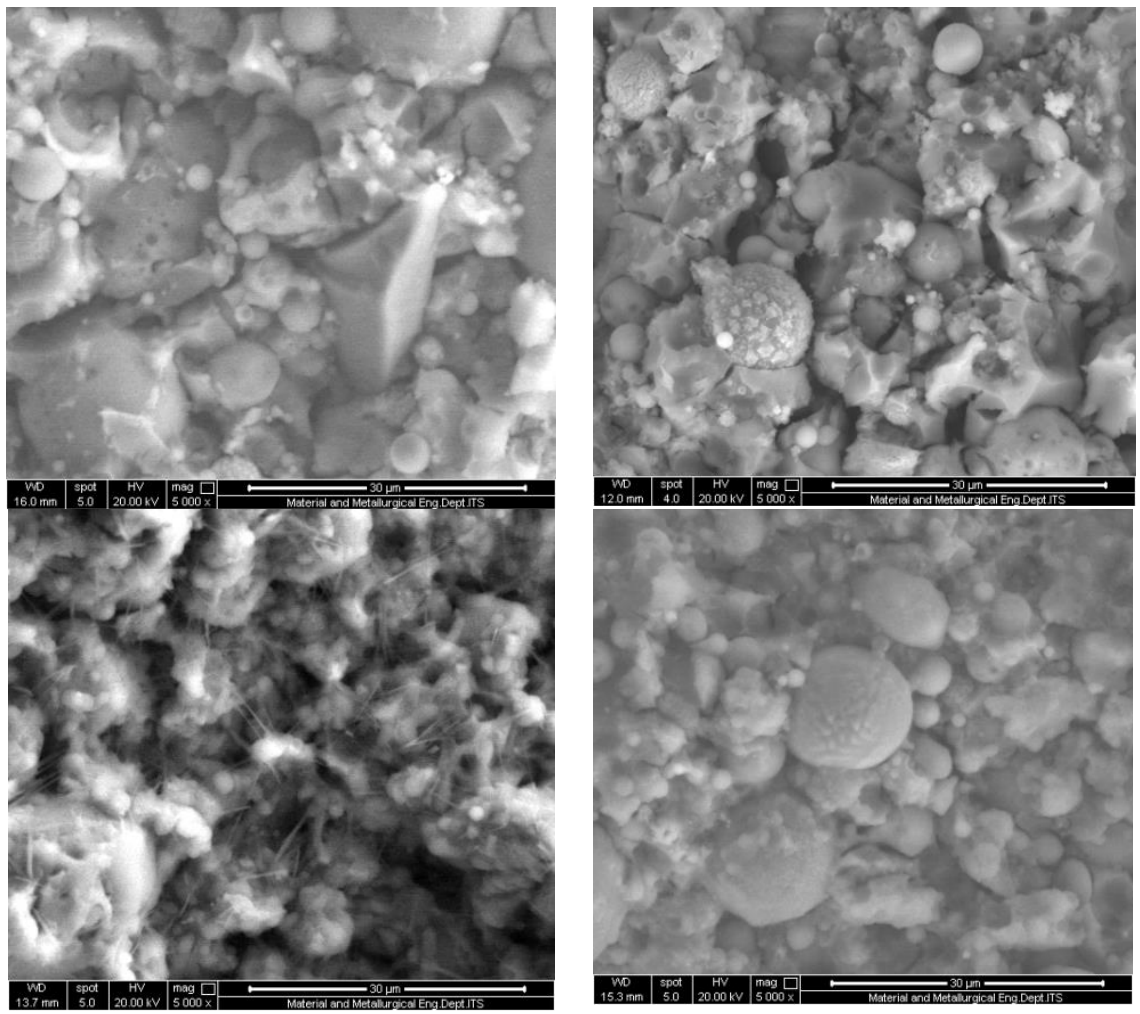

Fig. 2. SEM images of geopolymer with variation solid/liquid weight ratio of (a) 60:40, (b) 65:45, (c) $70: 30$, (d) $75: 35$.

\subsection{Water absorption capacity measurement}

Water absorption capacity of geopolymer samples with variation of solid-liquid ratio depicted in Fig. 3. Solid-liquid ratio of 60:40 resulted 11,10\% water absorption. Meanwhile $65: 35$ resulted $10,89 \%$. Maximum capacity of water absorption is $13,04 \%$ with $70: 30$ ratio of salod-liquid. Solid phase contain fly ash and $\mathrm{KCl}$. Liquid phase contain $\mathrm{Na}_{2} \mathrm{SO}_{3}, \mathrm{NaOH}$ $3 \mathrm{M}$. After reached optimum condition that caused Geopolymer has maximum ability to absorp water. Increasing of liquid ratio at $75 \%$ decrease ability of geopolymer to absorp water significantly at $4,39 \%$.

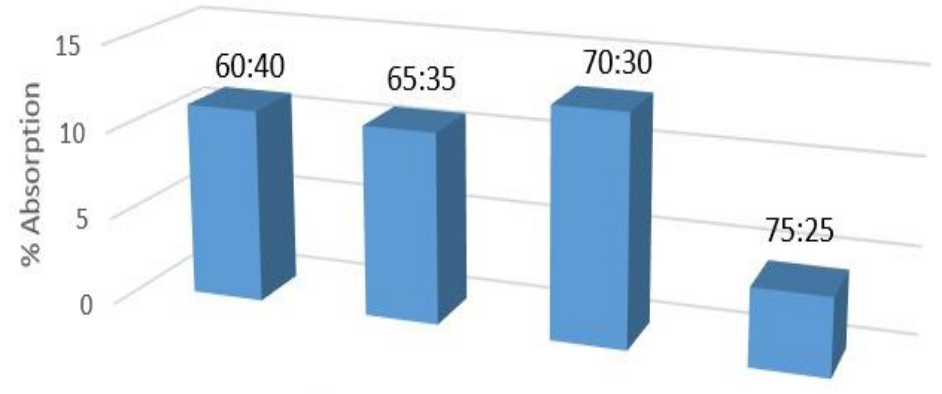

- Solid-Liquid Ratio

Fig. 3. Water absorption capacity of geopolymer samples with variation of solid-liquid ratio. 


\section{Summary}

Geopolymer has been synthesized from fly ash as an aluminosilicate source with variations of solid-liquid 60:40, 65:35, 70:30, and 75:25 with $3 \mathrm{M}$ of $\mathrm{NaOH}$. The XRD confirmed that all variation resulted geopolymer phase. SEM images of geopolymer with solid/liquid weight ratio of 70:30 show the smallest particle size, so the material produce high specific area and high water abrsorption capacity. It is proved Water Absorption Capacity Measurement that confirmed with 70:30 ratio of solid-liquid resulted 13,04\%wt.

The authors wish to thank LPPM UISI for providing Hibah Riset Bersaing UISI, contract number 03/KP.01/10-01/02.16 date February $19^{\text {th }}, 2016$

\section{References}

1. B. Cohen B., Technol. Soc., 28 (2006)

2. K. Okada, S. Matsui, T. Isobe, Y. Kameshima, A. Nakajima, Ceram. Intern., 34 (2008)

3. J. Davidovits, Therm. Anal., 37 (1991)

4. S. Thokchom, P. Ghosh, S. Ghosh, ARPN Journal of Engineering and Applied Sciences, 4, (2009)

5. U. Rattanasak, P. Chindaprasirt, Min. Engine., 22 (2009)

6. Skvara, Frantisek, Kopecky, Lumboir, Nemecek, Jiri, Bittnar, Zdenek, Microstructure of Geopolymer Materials Based on Fly Ash, Original Paper, Ceram-Silikaty, 50 (2006)

7. P. Duxon, A. Ferandez Jimenez, J.L. Provis, G.C. Luckey, A. Palomo, J.S.J. Van Deventer, J. Mater. Sci, 42 (2007)

8. M.M.A. Abdullah, K. Hussin, M. Bnhussain, K.N. Ismail, W.M.W. Ibrahim, Int. Journal of Pure and App. Sci and Tech, 6 (2011)

9. K. Okada, A. Ooyama, T. Isobe, Y. Kameshima, A. Nakajima, K.J.D. MacKenzie, J Eur Ceram Soc., 29 (2009) 